\title{
DA PARAíBA AO ESTADO DO MARANHÃO: TRAJETÓRIAS DE GOVERNO NA AMÉRICA PORTUGUESA (SÉCULOS XVII E XVIII)
}

\author{
Fabiano Vilaca dos Santos \\ Doutor em História Social - FFLCH/USP
}

\section{Resumo}

Este artigo trata da conexão entre os governos da Paraíba e do Estado do Maranhão, nos séculos XVII e XVIII, a partir da análise das trajetórias e dos deslocamentos de agentes designados para a administração ultramarina. O nexo entre os dois postos encontrava respaldo nos critérios observados pela Coroa portuguesa na seleção dos governadores coloniais, bem como nas suas perspectivas de promoção no real serviço.

\section{Pallavras-chave}

Paraíba • Estado do Maranhão • trajetórias.

\section{Abstract}

This article tells of the connection between the governments of Paraíba and of the State of Maranhão, in the seventeenth and eighteenth centuries, from the analysis of the careers and the movement of the agents designated to the overseas administration. The connection between the posts was supported by the criteria observed by the Portuguese crown in the selection of the colonial governors, as well as their perspectives of promotion in the royal service.

\section{Keywords}

Paraíba • State of Maranhão $\bullet$ careers. 


\section{Paraíba e Maranhão: conquista e administração}

Nos últimos anos, a produção historiográfica dedicada ao estudo da colonização portuguesa tem privilegiado a análise do perfil dos agentes nomeados pela CCoroa para o governo ultramarino, relacionando suas origens familiares, formação e experiências no real serviço aos respectivos destinos. A consideração de um dos principais aspectos das trajetórias dos governadores, a sua circulação, produziu conclusões importantes, como a ideia de que os deslocamentos permitiram o "acúmulo de informações e a constituição de uma visão mais alargada do Império ultramarino na medida em que aqueles homens circulavam por mais de uma região". Além disso, os agentes a serviço do rei puderam desenvolver "uma percepção e uma compreensão acerca da diversidade dos problemas enfrentados, bem como da similitude de situações e de estratégias". ${ }^{1}$

A Coroa portuguesa, portanto, não observava apenas as origens pessoais, os vínculos de parentesco, as alianças familiares ou a formação dos homens indicados para servir no ultramar. Estes eram aspectos indubitavelmente relevantes na seleção dos governadores, mas, além da experiência - um atributo nem sempre ostentado -, conexões entre determinadas capitanias eram consideradas na escolha dos administradores coloniais, esboçando uma espécie de sentido para os seus percursos no real serviço. Um exemplo dessas articulações ocorreu entre a capitania da Paraíba e o Estado do Maranhão no século XVII e principalmente no XVIII.

A Paraíba e o Estado do Maranhão possuem algumas semelhanças em seu processo de conquista e colonização. A primeira foi criada no ano de 1574, em território desmembrado da capitania de Itamaracá, por iniciativa da Coroa, com o objetivo de defender a costa de incursões estrangeiras. Nesse sentido, foram organizadas, a partir de Pernambuco, expedições em 1574, 1575, 1582, 1584 e 1585 , ano em que a conquista foi oficializada com a fundação da capital, a cidade de Nossa Senhora das Neves. Em termos administrativos, a Paraíba era governada por capitães-mores nomeados pelo rei, os quais desfrutaram "autonomia administrativa" até o momento em que a capitania tornou-se subalterna a Pernambuco. ${ }^{2}$

\footnotetext{
${ }^{1}$ Cf. FRAGOSO, João Luís Ribeiro; GOUVÊA, Maria de Fátima Silva; BICALHO, Maria Fernanda Baptista. Uma leitura do Brasil colonial: bases da materialidade e da governabilidade no Império. Penélope, n. 23. Oeiras, 2000, p. 67-88. Ver p. 83.

${ }^{2}$ Cf. OLIVEIRA, Elza Régis de. Paraíba, capitania da. In: SILVA, Maria Beatriz Nizza da (coord.). Dicionário da história da colonização portuguesa no Brasil. Lisboa: Editorial Verbo, 1994. A Paraíba tornou-se subalterna a Pernambuco por carta régia de 29 de dezembro de 1755, confirmada em $1^{\circ}$ de janeiro do ano seguinte, situação que perdurou até 17 de janeiro de 1799 . Ver também
} 
Mais ao norte, a estrutura administrativa configurou-se da seguinte forma: de 1621 até 1751, vigorou o Estado do Maranhão e Grão-Pará, com sede em São Luís. Nessa época, o Maranhão correspondia à “cabeça" - uma expressão da época - do Estado, onde pontificava o governador e capitão-general ou simplesmente governador-geral. ${ }^{3}$ A capitania subalterna do Pará ficava a cargo de um capitão-mor. Apenas durante o curto período de 18 meses em que o Estado foi dissolvido, entre 1652 e 1654, houve um governador em Belém. A partir de 1751, quando foi criado o Estado do Grão-Pará e Maranhão, o governador e capitãogeneral passou a residir em Belém. Um subalterno no Maranhão ostentava o título de governador (com a patente de tenente-coronel) e não o de capitão-mor. ${ }^{4}$

A conquista da Paraíba e do Maranhão, contudo, não se deu sem obstáculos. O cronista João de Barros, primeiro donatário da Paraíba, encontrou dificuldades para colonizar o território, o que levou a Coroa a transferir para Frutuoso Barbosa, no final do século XVI, a missão de promover a ocupação daquelas terras. Mas teve que vencer a resistência dos índios potiguares, aliados aos franceses contrabandistas de pau-brasil. ${ }^{5}$ É justamente nesse ponto que a conquista da Paraíba se aproxima da conquista do Maranhão.

Capistrano de Abreu foi um dos que discorreu sobre o processo de ocupação do Maranhão. De Pernambuco partiu uma expedição ao Rio Grande do Norte, organizada pelo governador-geral, d. Francisco de Sousa, e chefiada por Alexandre de Moura e Manuel Mascarenhas Homem, ao qual se juntou Jerônimo de Albuquerque. Com o apoio do capitão-mor da Paraíba, Feliciano Coelho de

MENEZES MOZART, Vergetti de. Sonhar com o céu, padecer no inferno: governo e sociedade na Paraíba do século XVIII. In: BICALHO, Maria Fernanda; FERLINI, Vera Lúcia Amaral (orgs.). Modos de governar: ideias e práticas políticas no Império português (séculos XVI a XIX). São Paulo: Alameda, 2005, p. 327-340. Ver p. 327-328.

${ }^{3}$ Para a formação e a história administrativa do Estado do Maranhão, ver o artigo de WEHLING, Maria José Mesquita Cavaleiro de Macedo. O Estado do Maranhão na União Ibérica. Revista do Instituto Histórico e Geográfico Brasileiro, 166 (426), jan./mar. Rio de Janeiro, 2005, p. 57-86. ${ }^{4}$ Luís de Vasconcelos Lobo, nomeado para o Maranhão em 1751, inaugurou essa nova fase da administração do Estado, conforme registrado no princípio das instruções a Francisco Xavier de Mendonça Furtado. Cf. MENDONÇA, Marcos Carneiro de (coord). A Amazônia na era pombalina. Correspondência inédita do governador e capitãogeneral do Estado do Grão-Pará e Maranhão Francisco Xavier de Mendonça Furtado (1751-1759). São Paulo: Instituto Histórico e Geográfico Brasileiro, 1963, t. 1, p. 26. ${ }^{5}$ Cf. PITA, Sebastião da Rocha. História da América portuguesa, desde o ano de 1500 do seu descobrimento até o de 1724. Belo Horizonte: Ed. Itatiaia; São Paulo: Edusp, 1976, p. 56. Ver também SOUTHEY, Robert. História do Brasil. Tradução de Luís Joaquim de Oliveira e Castro. Belo Horizonte: Ed. Itatiaia; São Paulo: Edusp, 1981, vol. 1, p. 251-252. 
Carvalho, Mascarenhas Homem concluiu o Forte dos Reis Magos e o entregou ao comando de Jerônimo de Albuquerque. Segundo Capistrano de Abreu, a conquista do Rio Grande do Norte afastou os franceses e diminuiu a distância do Maranhão e Amazonas em relação a Pernambuco e Bahia, sede do governo-geral. ${ }^{6}$

Restava incorporar definitivamente o Maranhão à soberania portuguesa. Com esse objetivo, partiu da Paraíba, em 1603, a expedição de Pedro Coelho de Sousa. Ao chegar ao rio Jaguaribe, no Ceará, o comandante selou a paz com os índios a fim de percorrer livremente o litoral da capitania. Mas, na serra de Ibiapaba, encontrou resistência dos franceses e teve que recuar. Outra expedição ao Maranhão, auxiliada por índios capturados por Pedro Coelho de Sousa, foi confiada aos jesuítas Luís Figueira e Francisco Pinto pelo governador-geral, d. Diogo de Meneses. Contudo, um assalto de índios hostis à aldeia onde se encontravam os missionários, que resultou na morte do padre Francisco Pinto, fez com que as tentativas de chegar ao Maranhão mais uma vez não ultrapassassem a serra de Ibiapaba. Com isso, ficou claro que era preciso consolidar a conquista do Ceará. ${ }^{7}$

Estava aberto o caminho para a iniciativa de Martim Soares Moreno que, aliado aos índios potiguares, de quem aprendera a língua, solidificou a presença luso-brasileira no Ceará por meio da construção de uma fortificação que serviu de base aos conquistadores e ao afastamento dos franceses. A expansão rumo ao Maranhão continuou com Jerônimo de Albuquerque que se juntou a Martim Soares Moreno. Na baía de São José, a armadilha dos tupinambás associados aos invasores, comandados por Daniel de La Touche, senhor de La Ravardière, adiou a conquista até a organização de uma segunda expedição, confiada em 1614 a Jerônimo de Albuquerque, auxiliado por Diogo de Campos. No ano seguinte, os reforços das tropas de Francisco Caldeira de Castelo Branco e de Alexandre de Moura determinaram a expulsão dos franceses de São Luís e, mais tarde, do Pará. ${ }^{8}$

Resistência indígena e presença francesa, portanto, são elementos comuns à conquista da Paraíba e do Maranhão e fazem parte de um quadro mais amplo, sintetizado por A. J. R. Russell-Wood. Segundo o historiador, nos idos de 1567, os franceses liderados por Nicolas Durand de Villegaignon foram expulsos da baía da Guanabara, frustrando-se o projeto da França Antártica, e “depois de uma

\footnotetext{
${ }^{6}$ ABREU, João Capistrano de. Capitulos de história colonial: 1500-1800. 6 a ed. Rio de Janeiro: Civilização Brasileira; Brasília: INL, 1976, p. 59-60. Ver também CORTESÃO, Jaime. História da expansão portuguesa. Lisboa: Imprensa Nacional; Casa da Moeda, 1993, p. 390-393.

${ }^{7}$ ABREU, João Capistrano de, op. cit., 1976, p. 60-61.

${ }^{8}$ Ibidem, p. 61-67.
} 
década de intensa atividade francesa, durante a qual foi fundada São Luís (1594) no Maranhão e ocupada a Paraíba, os franceses acabaram por se render, em 1615". ${ }^{9}$ Mas as iniciativas lusas, somadas aos esforços dos colonos, não foram suficientes para livrar a costa da presença do invasor. Como salientou RussellWood, as vitórias das armas portuguesas, somadas aos esforços dos colonos, não foram suficientes para "dissuadir um ataque ao Rio de Janeiro, em 1710, comandado por Du Clerc, que falhou, nem outro, desta vez Coroado de êxito e seguido de breve ocupação (...), de René Duguay-Trouin", no ano seguinte. ${ }^{10}$

Em linhas gerais, os fatos acima têm relação com o perfil dos ocupantes dos cargos de capitão-mor da Paraíba e de governador e capitão-general do Estado do Maranhão, posto que em momento posterior ao das respectivas fundações e consolidação da conquista. E como o propósito deste artigo é abordar os percursos dos agentes na administração colonial, é conveniente passar à discussão dos seus deslocamentos, observando-se algo que não é meramente formal: a denominação dos indivíduos de acordo com o cargo que ocupavam. Segundo Mafalda Soares da Cunha, é necessário considerar as distinções clássicas entre governo-geral, governos principais e de capitanias subalternas, uma vez que tal hierarquia está diretamente relacionada ao status social dos respectivos titulares. ${ }^{11}$

\section{As pretensões de um capitão-mor}

No ano de 1712, João da Maia da Gama, capitão-mor da Paraíba desde 1708, dirigiu um requerimento a d. João $\mathrm{V}$ solicitando o envio de um sucessor e a remuneração de seus serviços à frente daquele governo. O pedido estava fundamentado em ações recentes no sentido de defender a capitania de um eventual ataque francês, e de garantir a obediência à autoridade régia ao contribuir para o restabelecimento da paz em Pernambuco após o atentado contra o governador Sebastião de Castro e Caldas. ${ }^{12}$

\footnotetext{
${ }^{9}$ RUSSELL-WOOD, A. J. R. Um mundo em movimento: os portugueses na África, Ásia e América (1415-1808). Tradução de Vanda Anastácio. Lisboa: Difel, 1998, p. 43. O historiador considera o ano de 1594 como o da fundação de São Luís. De fato, a presença francesa remonta àquela data, quando, segundo Jaime Cortesão, os invasores transformaram a ilha de São Luís em "base naval de todos os flibusteiros franceses". Cf. CORTESÃO, Jaime, op. cit., 1993, p. 390. Contudo, a data mais aceita para a fundação da cidade é 1612 .

${ }^{10}$ RUSSELL-WOOD, A. J. R., op. cit., 1998, p. 43.

${ }^{11}$ CUNHA, Mafalda Soares da. Governo e governantes do Império português doAtlântico (século XVII). In: BICALHO, Maria Fernanda; FERLINI, Vera LúciaAmaral (orgs.), op. cit., 2005, p. 69-92. Verp. 82.

${ }^{12}$ Arquivo Histórico Ultramarino (doravante AHU) - Projeto Resgate. Paraíba (avulsos), cd 1,
} 
A petição de Maia da Gama reiterava outra, enviada dois anos antes, na qual deixara explícito o desejo de ser "acrescentado", ou seja, recompensado por seus préstimos, com o governo de Pernambuco ou do Rio de Janeiro, "visto o grande serviço que tinha feito à Coroa" na Paraíba. Se, no início da petição de 1712, repetia a solicitação de um daqueles dois governos, no final, sem dizer o porquê, substituiu Pernambuco por Minas Gerais, o que pode ser interpretado como efeito da atração exercida pelos veios auríferos. Tais pretensões, contudo, estavam muito além das possibilidades de um indivíduo de origem obscura.

João da Maia da Gama nasceu em Aveiro, na Beira, em 1673. Era filho de Pedro Ribeiro de Oliveira e de d. Luísa da Gama. Não há muitas informações sobre a sua família, mas é de supor que tivesse algumas posses. Consta que Maia da Gama estudou Filosofia na Universidade de Coimbra, mas abandonou o curso para ingressar na carreira das armas. Sua primeira participação no real serviço se deu ao acompanhar d. Pedro Antônio de Noronha de Albuquerque, $2^{\circ}$ conde de Vila Verde e $1^{\circ}$ marquês de Angeja, nomeado vice-rei da Índia (1693-1698) e, mais tarde, do Estado do Brasil (1714-1718). De acordo com um seu biógrafo, nada imparcial, teria enfrentado muitas tormentas e doenças a caminho do Oriente. Em 1694, tripulou a galeota Nossa Senhora da Conceição e percorreu a costa da Índia enfrentando embarcações inglesas que pirateavam em águas portuguesas. ${ }^{13}$

Combateu os árabes que ameaçavam o domínio lusitano nas feitorias de Surrate e de Ormuz, sofrendo, nesta última, grave ferimento de caitoca, um tipo de arma de fogo. Pelos feitos realizados, foi recompensado com o posto de capitão-de-fragata de uma nau capitânia da Índia. Resistiu aos árabes em Mombaça, mas acabou retornando a Lisboa em dezembro de 1698, na companhia do marquês de Angeja. Dois anos depois, recebeu novamente a mercê de um posto na embarcação que capitaneava a carreira da Índia e, em 1702, chegou a capitão de mar-e-guerra da fragata Nossa Senhora do Bonsucesso,

cx. 4 , doc. 335 .

${ }^{13}$ MARTINS, F. A. Oliveira. Um herói esquecido (João da Maia da Gama). Lisboa: Agência Geral das Colônias, 1944, vol. 1, p. 11-20. João da Maia da Gama faleceu em 11 de novembro de 1731 e foi sepultado no Convento dos Eremitas de São Paulo, na freguesia de Santa Catarina do Monte Sinai, onde morava. Há divergências quanto ao seu estado civil. Segundo o biógrafo, o registro de óbito diz que Maia da Gama era solteiro, mas o militar teria se casado em Guimarães com d. Luísa Jacinta Caetana de Figueiredo Morgado. Desta união teriam nascido cinco filhos: frei Francisco da Maia da Gama (carmelita descalço), d. Mariana Teresa Abranches Pinto de Figueiredo, d. Antônia Genoveva, d. Joana e d. Catarina da Maia da Gama, todas casadas, exceto a última (p. 83-84). 
destinada a socorrer Mombaça, tomada pelos árabes de Omã com o auxílio de ingleses e de holandeses. ${ }^{14}$

O plano de acudir a praça da África oriental foi adiado em função dos males adquiridos por Maia da Gama nas lutas em Ormuz e de um sinistro ocorrido em uma escala na Bahia: o incêndio da fragata Nossa Senhora do Bonsucesso. Para remediar a situação, adquiriu a nau Santa Escolástica. Consciente do valor dos serviços à Coroa e da importância de restaurar o domínio português em Mombaça - análise que o seu biógrafo não fez - armou e tripulou a Santa Escolástica à custa de cabedal familiar. Contudo, visivelmente apartado da sorte, assistiu, ainda na Bahia, ao naufrágio da embarcação que aprestara, sacrificando os bens de uma irmã e de um sobrinho, compensados pela Coroa com a mercê de uma tença no valor de 160 mil réis. ${ }^{15}$

A participação do militar não se encerrou devido aos insucessos na campanha para retomar Mombaça. Durante a Guerra da Sucessão Espanhola, João da Maia da Gama se engajou na Cavalaria, sob as ordens de Manuel Carlos da Cunha e Távora, $4^{\circ}$ conde de São Vicente. Combateu as tropas franco-espanholas em Castelo de Vide, no Alentejo, e, em 1705, pelejou em defesa de Gibraltar, também assolada pelos franceses. Sem dúvida, a atuação na Guerra da Sucessão Espanhola foi - até aquele momento - o corolário dos serviços de Maia da Gama e a sua credencial para assumir o cargo de capitão-mor da Paraíba, para o qual foi nomeado por carta de 12 de abril de $1708 .{ }^{16}$

Não cabe detalhar a ação administrativa de Maia da Gama à frente da capitania, mas tão-somente retomar a discussão proposta neste tópico, fundada no requerimento do capitão-mor de uma promoção ao governo de Pernambuco, do Rio de Janeiro ou de Minas. Para a defesa da Paraíba ante a ameaça de uma incursão francesa, Maia da Gama conclamou a população a guarnecer os portos e praias que poderiam servir como local de desembarque. Montou quartéis, repartiu soldados e oficiais pela Infantaria e a Cavalaria, construiu pontes e despachou embarcações para manter de sobreaviso toda a costa. Em seguida, juntamente com as ordenanças, recolheu-se à Fortaleza do Cabedelo, reparada nos baluartes e cortinas, a fim de aguardar a esquadra inimiga. ${ }^{17}$

\footnotetext{
${ }^{14}$ Ibidem, p. 21-29. Sobre a tomada de Mombaça aos portugueses, ver, por exemplo, RUSSELLWOOD, A. J. R., op. cit., 1998, p. 42.

${ }^{15}$ MARTINS, F. A. Oliveira, op. cit., 1944, vol. 1, p. 30-31.

${ }^{16}$ Ibidem, p. 35-43.

${ }^{17}$ AHU - Projeto Resgate. Paraíba (avulsos), cd 1, cx. 4, doc. 335. A representação, supostamente
} 
Como em vários outros episódios relativos à defesa das conquistas ultramarinas, nada disso foi feito sem o dispêndio de esforços e de cabedais dos colonos e, nesse caso, do próprio capitão-mor, que carregara "cestos sem diferença como o mais humilde soldado" e não recebia soldo havia quase três anos. ${ }^{18}$ No que se refere ao episódio conhecido como a Guerra dos Mascates, envolvendo os comerciantes do Recife e os senhores de engenho de Olinda, João da Maia da Gama foi ainda mais enfático ao realçar sua contribuição para a manutenção do sossego e da autoridade de sua majestade sobre aqueles súditos levantados. ${ }^{19}$

Para tanto, o capitão-mor mandou os desembargadores Cristóvão Soares Reimão e Manuel Velho de Miranda e o ouvidor Jerônimo Correia do Amaral conterem os revoltosos do Recife e forçá-los a aceitar o bispo de Olinda - $\mathrm{d}$. Manuel Álvares da Costa - como seu governador, após a fuga de Sebastião de Castro e Caldas. ${ }^{20} \mathrm{O}$ feito, segundo Evaldo Cabral de Mello, não seria esquecido. Em suas palavras, "João da Maia da Gama reivindicará o mérito da iniciativa". ${ }^{21}$ É o que demonstra o requerimento em análise.

Mais tarde, quando a Coroa enviou Félix José Machado para governar Pernambuco e aplacar definitivamente os ânimos exaltados, Maia da Gama teria sido o responsável pela entrada do novo governador em sua jurisdição e por que se "fizesse, ou guardasse obediência às justiças de Vossa Majestade". Por tudo isso, segundo o próprio capitão-mor, "a ele, João da Maia da Gama, e não a outrem, deve principalmente Vossa Majestade o ter na sua real obediência todas estas capitanias desde o Rio de S. Francisco até o Ceará". ${ }^{22}$

Tais alegações corroboram as considerações de Evaldo Cabral de Mello, para quem as atitudes do capitão-mor da Paraíba - que exorbitaram a sua jurisdição e levaram à reprimenda do governador-geral, d. Lourenço de Almada - tinham o único propósito de colocá-lo na condição de "mediador" em prol da nobreza pernambucana, ameaçada pelos mascates do Recife. ${ }^{23}$ De outro modo, Maia da Gama também agiu como um manipulador da lealdade dos olindenses, lembrando-lhes a condição de filhos e netos dos que haviam libertado Per-

\footnotetext{
de 1710, é mencionada no requerimento enviado a d. João V em 1712.

${ }^{18}$ Idem.

${ }^{19}$ Sobre a Guerra dos Mascates, ver MELLO, Evaldo Cabral de. A fronda dos mazombos: nobres contra mascates. Pernambuco, 1666-1715. 2 a ed. São Paulo: Editora 34, 2003.

${ }^{20}$ AHU - Projeto Resgate. Paraíba (avulsos), cd 1, cx. 4, doc. 335.

${ }^{21}$ MELLO, Evaldo Cabral de, op. cit., 2003, p. 331.

${ }^{22}$ AHU - Paraíba (avulsos), cd 1, cx. 4, doc. 335.

${ }^{23}$ MELLO, Evaldo Cabral de, op. cit., 2003, p. 303.
} 
nambuco do domínio holandês. ${ }^{24}$ Quanto a colaborar para a entrada de Félix José Machado, João da Maia da Gama teria merecido, além da repreensão do governador-geral, uma crítica do Conselho Ultramarino por se intrometer na repressão aos revoltosos de Pernambuco. ${ }^{25}$

Embora Maia da Gama se mostrasse extremamente confiante e seguro de que suas demandas seriam satisfeitas pela benemerência régia, não foi agraciado com a nomeação para qualquer um dos cargos que pleiteara. Em 1717, após quase 10 anos na Paraíba, foi substituído e voltou para o Reino. Não ficou, todavia, sem remuneração. Anos depois, obteve novamente o reconhecimento de sua experiência militar, como será mencionado adiante. Do ponto de vista da escolha dos agentes para o serviço no ultramar, os critérios para o acesso aos cargos cobiçados pelo antigo capitão-mor da Paraíba merecem uma breve caracterização, o que indiretamente lançará luz sobre o circuito aqui privilegiado.

\section{Destinos de fidalgos: Pernambuco, Minas Gerais e Rio de Janeiro}

Desde o século XVII, os governos de Pernambuco e do Rio de Janeiro demonstravam uma "prevalência de fidalgos" entre os seus ocupantes, de acordo com Nuno Gonçalo Monteiro e Mafalda Soares da Cunha ${ }^{26}$ Cerca de duas décadas antes da presença de João da Maia da Gama na América portuguesa, alguns representantes da alta nobreza, titulados ou não, podem ser identificados entre os que governaram Pernambuco. De 1690 a 1693, esteve à frente da capitania o $2^{\circ}$ marquês de Montebelo, Antônio Félix da Silva Machado e Castro, um fidalgo cuja família foi reabilitada pela Casa de Bragança. Seu pai servira como embaixador de Castela em Roma e permanecera na Espanha após a Restauração. Estabelecido em Portugal, Antônio Félix conseguiu recuperar os bens da família outrora confiscados, embora não dispusesse de alianças sólidas na corte, como sublinhou Evaldo Cabral de Mello. ${ }^{27}$ Mais tarde, o filho de Montebelo, Félix José Machado (1711-1715), foi também nomeado governador de Pernambuco e encarregado de reprimir os conflitos entre mazombos e mascates.

\footnotetext{
${ }^{24}$ Cf. MELLO, Evaldo Cabral de. Rubro veio: o imaginário da restauração pernambucana. $2^{\mathrm{a}}$ ed. Rio de Janeiro: Topbooks, 1997, p. 123-124.

${ }^{25}$ MELLO, Evaldo Cabral de, op. cit., 2003, p. 457.

${ }^{26}$ CUNHA, Mafalda Soares da. Governo e governantes do Império português do Atlântico (século XVII). In: BICALHO, Maria Fernanda; FERLINI, Vera Lúcia Amaral (orgs.), op. cit., 2005, p. 83. ${ }^{27}$ MELLO, Evaldo Cabral de, op. cit., 2003, p. 74-75.
} 
O sucessor de Montebelo, Caetano de Melo e Castro (1693-1699), também era um indivíduo de melhor extração social que João da Maia da Gama. Era oriundo de família com tradição no governo da Índia - seu bisavô, Francisco de Melo e Castro, foi conselheiro de governo, assim como seu filho (avô paterno de Caetano de Melo e Castro), Antônio de Melo e Castro, que chegou a vice-rei (1662-1666). No seio desta família nasceu Diniz de Melo e Castro, $1^{\circ}$ conde das Galveias, cuja Casa prestaria relevantes serviços à monarquia ao longo do século XVIII. Caetano de Melo e Castro procurou cultivar boas alianças no âmbito da corte. Casou-se com d. Mariana de Faro, filha de Francisco Carneiro de Sousa, $2^{\circ}$ conde da Ilha do Príncipe, e neta pelo lado materno de d. Francisco de Sousa, $3^{\circ}$ conde do Prado e $1^{\circ}$ marquês das Minas..$^{28}$

Sebastião de Castro e Caldas, que Maia da Gama tanto se esforçou para acudir, era oriundo de uma família do Minho (norte de Portugal), mais afastado dos círculos cortesãos que seus antecessores, porém dotado de mais distinção que Maia da Gama. Filho segundo de um morgado de Arcos de Valdevez era, portanto, representante de uma elite provincial que geralmente não possuía títulos de nobreza ou senhorios jurisdicionais, mas dispunha de riqueza baseada na posse de bens vinculados ou não. ${ }^{29}$

Como era costume nos diferentes círculos da nobreza, Castro e Caldas ingressou na carreira das armas muito jovem, apadrinhado pelo tio Diogo de Caldas Barbosa. ${ }^{30}$ E construiu uma folha de serviços respeitável. Participou dos derradeiros momentos das guerras da Restauração, especialmente na Batalha de Montes

\footnotetext{
${ }^{28}$ Cf. ZÜQUETE, Afonso Eduardo Martins. Tratado de todos os vice-reis e governadores da Índia. Lisboa: Editorial Enciclopédia, 1962, p. 157. Ver também, do mesmo autor, Nobreza de Portugal e do Brasil, vol. 2. $3^{\mathrm{a}}$ ed. Lisboa: Edições Zairol, 2000, p. 657 e p. 742-743. O $2^{\circ}$ conde da Ilha do Príncipe lutou na Guerra da Sucessão Espanhola, enquanto o $1^{\circ}$ marquês das Minas foi um dos que aclamou d. João IV e participou de várias escaramuças para expulsar os últimos efetivos espanhóis que insistiam em sitiar pontos estratégicos de Portugal. Foi governador das armas, embaixador junto à Santa Sé, conselheiro de Estado e da Guerra e presidente do Conselho Ultramarino. Ver SOUSA, D. Antônio Caetano de. História genealógica da Casa Real portuguesa, t. XII, parte II. $2^{\mathrm{a}}$ ed. Coimbra: Atlântida, 1946, p. 137. GAYO, Felgueiras. Nobiliário das famílias de Portugal, vol. II e vol. IV. $2^{\text {a }}$ ed. Braga: Edições Carvalhos de Basto, 1989, vol. I, p. 372 e vol. IV, p. 252-253. CUNHA, Mafalda Soares da; MONTEIRO, Nuno Gonçalo. Vice-reis, governadores e conselheiros de governo do Estado da Índia (1505-1834). Recrutamento e caracterização social. Penélope, n. ${ }^{\circ}$ 15. Lisboa, 1995, p. 91-120. Ver p. 105-106.

${ }^{29}$ Cf. MELLO, Evaldo Cabral de, op. cit., 2003, p. 218. Ver também MONTEIRO, Nuno Gonçalo. Elites e poder: entre o Antigo Regime e o liberalismo. Lisboa: Imprensa de Ciências Sociais; Instituto de Ciências Sociais da Universidade de Lisboa, 2003, p. 75-80.

${ }^{30}$ Cf. PITA, Sebastião da Rocha. História da América portuguesa, desde o ano de 1500 do seu descobrimento até o de 1724. Belo Horizonte: Ed. Itatiaia; São Paulo: Edusp, 1976, p. 247.
} 
Claros, em 1665. Galgou postos importantes no Exército e, em reconhecimento de seus préstimos em favor da consolidação no poder da Casa de Bragança, recebeu a indicação para capitão-mor da Paraíba, a qual recusou. ${ }^{31}$ Não fosse isso, sua trajetória se assemelharia à de João da Maia da Gama. Mas, no que diz respeito ao valor atribuído aos seus próprios serviços, ambos se aproximavam.

Ao declinar da Paraíba, Sebastião de Castro e Caldas preferiu ser governador interino do Rio de Janeiro, capitania de melhor posição na hierarquia dos cargos na América portuguesa. Teve que responder a acusações de improbidade no retorno a Portugal, mas foi logo reabilitado. Reengajado no Exército, participou da Guerra da Sucessão Espanhola. Querendo talvez dissimular a modéstia em eventual pedido de remuneração, solicitou o mesmo cargo que havia dispensado: o de capitão-mor da Paraíba. Não foi atendido, recebendo em troca a nomeação para a Colônia do Sacramento, necessitada da direção de um militar experiente, principalmente naquela conjuntura de guerra em que Portugal e Espanha estavam em lados opostos. Outra recusa - e quiçá alguma interferência superior - acabou franqueando a Castro e Caldas o acesso a um governo mais prestigioso: o de Pernambuco. ${ }^{32}$

O terceiro governador a desembarcar em Pernambuco após a desdita de Sebastião de Castro e Caldas, d. Lourenço de Almeida (1715-1718), estava mais próximo dos círculos cortesãos por ser filho do $2^{\circ}$ conde de Avintes, d. Antônio de Almeida Portugal, e de d. Maria Antônia de Bourbon, filha do $3^{\circ}$ conde dos Arcos, d. Tomás de Noronha. Tinha como irmão d. Tomás de Almeida que viria a ser o primeiro patriarca de Lisboa. Além disso, d. Lourenço tinha aliados de prestígio na corte: seu cunhado, o secretário Diogo de Mendonça Corte Real (o velho), e o $1^{\circ}$ marquês de Angeja, a quem acompanhou à Índia. ${ }^{33}$

D. Lourenço de Almeida era ainda cunhado de d. Álvaro da Silveira e Albuquerque, governador do Rio de Janeiro (1703-1705), casado em segundas núpcias com uma irmã do primeiro, d. Teresa de Bourbon. Nesse sentido, o parentesco entre ambos os administradores coloniais evidencia o acesso aos governos de Pernambuco e do Rio de Janeiro de indivíduos de boa estirpe e bem articulados

\footnotetext{
${ }^{31}$ Cf. MELLO, Evaldo Cabral de, op. cit., 2003, p. 218.

${ }^{32}$ Ibidem, p. 218-219.

${ }^{33}$ Cf. MELLO, Evaldo Cabral de, op. cit., 2003, p. 458. Ver também SANTOS, Fabiano Vilaça dos. Mediações entre a fidalguia portuguesa e o marquês de Pombal: o exemplo da Casa de Lavradio. Revista Brasileira de História, vol. 24, n 48. São Paulo, p. 321-329. Ver p. 303.
} 
no cenário político e social da corte. A circulação pelos dois postos também foi uma realidade, ao menos no início do Setecentos, como será visto adiante.

No que se refere à sua trajetória administrativa, d. Lourenço de Almeida exemplificou a conexão entre os governos de Pernambuco e de Minas Gerais. ${ }^{34}$ Esteve neste último de 1721 a 1732, tendo sido o primeiro a ocupá-lo depois da divisão da capitania de São Paulo e Minas do Ouro. Antes dele, a extinta unidade foi administrada por dois elementos com boas relações na corte e diferentes inserções na hierarquia nobiliárquica: d. Brás Baltazar da Silveira (1713-1717) e d. Pedro Miguel de Almeida Portugal, $3^{\circ}$ conde de Assumar (1717-1721).

D. Brás Baltazar ascendeu socialmente não apenas em razão da grande (e escusa) fortuna que amealhou nas Minas, ${ }^{35}$ mas graças aos dois casamentos. Ao contrair matrimônio com d. Joana Inês Vicência de Meneses, ligou-se a uma Casa com tradição no exercício de ofícios palatinos. A noiva era filha de Aleixo de Sousa da Silva e Meneses, $2^{\circ}$ conde de Santiago de Beduído, $7^{\circ}$ aposentador-mor da Casa Real, além de deputado da Junta dos Três Estados. ${ }^{36}$ Viúvo, casou-se com d. Maria Caetana de Noronha, filha do $1^{\circ}$ conde de Povolide, Tristão da Cunha de Ataíde e Melo, proveniente de um ramo secundário da família Cunha (do principal era membro o diplomata d. Luís da Cunha), porém, dotado de "melhores alianças" (Tristão de Ataíde era irmão do inquisidor-geral d. Nuno da Cunha, cardeal da Cunha). ${ }^{37}$

Segundo Nuno Gonçalo Monteiro, o patrimônio da Casa de Povolide foi constituído a partir de enlaces vantajosos de seus senhores ao longo dos séculos XVI e XVII, mas o que mais contribuiu para a titulação do $10^{\circ}$ senhor de Povolide foi a herança dos bens de um seu tio, Nuno da Cunha e Ataíde, primeiro e único conde de Pontével. ${ }^{38}$ Ademais, um dos cunhados de d. Brás Baltazar, d.

\footnotetext{
${ }^{34}$ Outro governador que percorreu esse circuito, na segunda metade do século XVIII, foi Luís Diogo Lobo da Silva. Ver SOUZA, Laura de Mello e. A remuneração dos serviços: Luís Diogo Lobo da Silva. In: ... O sol e a sombra: política e administração na América portuguesa do século XVIII. São Paulo: Companhia das Letras, 2006, p. 327-349.

${ }^{35}$ Cf. SOUZA, Laura de Mello e. In: op. cit., 2006, p. 298.

${ }^{36}$ Cf. ZÜQUETE, Afonso Eduardo M., op. cit., 2000, vol. 3, p. 305.

${ }^{37}$ Cf. GAYO, Felgueiras, op. cit., 1989, vol. III, p. 417 e vol. VI, p. 399. Ver também CANEDO, Francisco de Castro da Silva. A descendência portuguesa de el rei d. João II. $2^{\mathrm{a}}$ ed. Braga: Edições Carvalhos de Basto, 1993, vol. I, p. 196. MONTEIRO, Nuno Gonçalo. Poder senhorial, estatuto nobiliárquico e aristocracia. In: HESPANHA, Antônio Manuel (coord.). História de Portugal - vol. 4: O Antigo Regime. Lisboa: Editorial Estampa, 1998, p. 297-338. Ver p. 325

${ }^{38}$ Sobre o patrimônio e a titulação da família Cunha, ver MONTEIRO, Nuno Gonçalo. O crepúsculo dos grandes: A Casa e o patrimônio da aristocracia em Portugal (1750-1832). $2^{\mathrm{a}}$ ed. Lisboa:
} 
Miguel da Anunciação, veio a ser bispo de Coimbra. Identificado como um dos principais opositores da política regalista do marquês de Pombal, foi destituído da mitra e encarcerado. ${ }^{39}$

Um dos fidalgos de maior projeção no governo de Minas foi, sem dúvida, d. Pedro Miguel de Almeida Portugal, $3^{\circ}$ conde de Assumar e $1^{\circ}$ marquês de Alorna. Administrou as Minas de 1717 a 1721, época em que rebentou a Revolta de Filipe dos Santos, e depois assumiu o vice-reinado da Índia (1744-1751). Laura de Mello e Souza considera o fidalgo, cuja família despontou no contexto da Restauração da independência de Portugal e da ascensão dos Bragança, "um dos governadores mais controvertidos da capitania de Minas Gerais". ${ }^{40}$ Independentemente da fama que conquistou, mercê da forma como reprimiu a revolta em Vila Rica, importa salientar que os percursos delineados pelo conde de Assumar na administração ultramarina também evidenciam uma conexão entre os governos de Minas e do Estado da Índia, dois postos de relevo no âmbito do Império colonial português. ${ }^{41}$ Pernambuco esteve de certa forma no meio desse circuito, uma vez que d. Lourenço de Almeida por lá passou antes de seguir para as Gerais.

Ao menos no início do século XVIII, houve também uma articulação entre os governos de Pernambuco e do Rio de Janeiro, exemplificada pela malfadada trajetória de Francisco de Castro Morais. Na primeira capitania (1703-1707), promoveu ampla reforma militar ao criar três regimentos com mais de mil homens para socorrer a costa em caso de uma invasão francesa ${ }^{42}$ No breve governo do Rio de Janeiro (1710-1711), em que deveria se aplicar com o mesmo afinco na defesa dos domínios de sua majestade, Castro Morais não conseguiu evitar

Imprensa Nacional; Casa da Moeda, 2003, p. 112-114. O historiador chamou atenção para a necessidade de considerar o papel dos tios no processo de enobrecimento de suas casas como legatários de bens e de serviços. Ver também, do mesmo autor, Elites e poder..., 2003, p. 77.

${ }^{39}$ Cf. GAYO, Felgueiras, op. cit., 1989, vol. III, p. 417 e vol. VI, p. 399. CANEDO, Francisco de Castro da Silva, op. cit., 1993, vol. I, p. 196. Ver também PAIVA, José Pedro. Os bispos de Portugal e do Império, 1495-1777. Coimbra: Imprensa da Universidade, 2006, p. 535.

${ }^{40}$ SOUZA, Laura de Mello e. Teoria e prática do governo colonial: D. Pedro de Almeida, conde de Assumar. In: ... O sol e a sombra..., 2006, p. 185-252.

${ }^{41}$ Sobre os critérios de seleção dos governadores do Estado da Índia e de outras capitanias de relevo na América portuguesa ver, por exemplo, MONTEIRO, Nuno Gonçalo. Trajetórias sociais e governo das conquistas: notas preliminares sobre os vice-reis e governadores-gerais do Brasil e da Índia nos séculos XVII e XVIII. In: FRAGOSO, João; BICALHO, Maria Fernanda; GOUVÊA, Maria de Fátima (orgs.). O Antigo Regime nos trópicos: a dinâmica imperial portuguesa (séculos XVI-XVIII). Rio de Janeiro: Civilização Brasileira, 2001, p. 258-283.

${ }^{42}$ Cf. MELLO, Evaldo Cabral de, 2003, p. 199 (nota 111). Ver também GAYO, Felgueiras, op. cit., 1989, vol. I, p. 282 e vol. VIII, p. 144. 
os inimigos. Teve êxito no confronto com as tropas do corsário Du Clerc, mas não deu mostras de valor no combate aos invasores comandados por DuguayTrouin, cerca de um ano depois. Abandonou o Rio de Janeiro, desarticulando a sua defesa, e capitulou vergonhosamente, permitindo que os franceses tomassem a cidade com relativa facilidade. Teve que aceitar os termos da rendição impostos pelo invasor e, diante do ocorrido, caiu em desgraça. ${ }^{43}$

Por fim, um caso que ilustra a amplitude que uma trajetória administrativa pode alcançar é o de Antônio de Albuquerque Coelho de Carvalho, o moço. Nos idos de 1660, acompanhou o pai, nomeado governador e capitão-general do Estado do Maranhão, na jornada até São Luís. Mais tarde, Antônio de Albuquerque, o moço, foi capitão-mor do Pará (1685-1690), subalterno ao Maranhão, e entre a última década do século XVII e o limiar do XVIII ocupou o cargo exercido por seu pai (1690-1701). ${ }^{44}$ Até então, os percursos do moço haviam obedecido a uma espécie de estratégia de sucessão familiar, verificada na distribuição dos postos governativos. Contudo, Antônio de Albuquerque deu um salto em sua carreira no ultramar. Das conquistas do Norte passou ao governo de São Paulo e Minas do Ouro e teve que assumir a capitania do Rio de Janeiro quando Francisco de Castro Morais foi destituído. ${ }^{45}$ Com isso, concentrou uma gama de poderes que chegou, inclusive, a despertar o apetite do conde de Assumar. ${ }^{46}$

A breve exposição das credenciais de acesso a determinados governos de projeção na América portuguesa (não se deve esquecer a Bahia), bem como a análise das pretensões de João da Maia da Gama aos mesmos postos, longe de particularizar ou restringir a análise da circulação dos agentes da colonização, amplia a discussão acerca de um tipo de circuito aberto a Maia da Gama e a outros indivíduos que deixaram a Paraíba para exercer um segundo, e até um terceiro, governo colonial. ${ }^{47}$ Conforme a análise feita neste tópico, desdobrada no próximo, a promoção na administração ultramarina obedecia a critérios diferenciados.

\footnotetext{
${ }^{43}$ Cf. PITA, Sebastião da Rocha, op. cit., 1976, p. 251-256.

${ }^{44}$ Cf. SOUZA, Laura de Mello e, op. cit., 2006, p. 122 (nota 28).

${ }^{45}$ Cf. PITA, Sebastião da Rocha, op. cit., 1976, p. 245-247 e p. 256.

${ }^{46}$ Cf. SOUZA, Laura de Mello e, op. cit., 2006, p. 245.

${ }^{47}$ Análise que se tornou referência sobre a nomeação de governadores e outros servidores régios para as diversas partes do Império português foi feita por RUSSELL-WOOD, A. J. R. Governantes e agentes. In: BETHENCOURT, Francisco; CHAUDHURI, Kirti (orgs.). História da expansão portuguesa, vol. 3. Lisboa: Círculo dos Leitores, 1998, p. 169-192.
} 


\section{Da Paraíba ao Estado do Maranhão}

Em sua História da América portuguesa, de 1730, Sebastião da Rocha Pita anotou:

Este lugar [a capitania da Paraíba] tem ocupado pessoas de suposição e serviços, que a ele passaram de grandes postos; e muitos deste governo foram ao do Estado do Maranhão e a outras ocupações militares de reputação, para as quais foi sempre degrau competente o governo da Paraíba. ${ }^{48}$

A caracterização de Rocha Pita não deixa dúvida quanto à existência de uma conexão entre o governo da Paraíba e o do Estado do Maranhão que, por sua vez, representava uma promoção para os que haviam passado pelo primeiro. Do ponto de vista da conquista do território e da defesa contra invasores estrangeiros e índios hostis, a Paraíba possui uma história similar à do Maranhão e mesmo do Pará, conforme abordado em linhas gerais no primeiro tópico deste artigo. Apesar dessas semelhanças, não é possível aceitar sem reservas a enfática constatação de Rocha Pita de que foram "muitos" os que passaram do governo da Paraíba ao do Estado do Maranhão. No que diz respeito à função governativa, poucos foram os agentes que realizaram tal deslocamento.

No século XVII, o caso de Antônio de Albuquerque ilustra a articulação entre os dois governos em tela, todavia, de modo inverso. "Empregado na conquista" do Maranhão, foi nomeado capitão-mor pelo pai, Jerônimo de Albuquerque Maranhão, tomando posse em 1618 e governando apenas um ano. De volta a Portugal, Antônio de Albuquerque recebeu, em recompensa pelos serviços prestados na expulsão dos franceses, uma comenda e o posto de capitão-mor da Paraíba. ${ }^{49}$ Uma observação necessária: em 1618, o Estado do Maranhão e Grão-Pará ainda não existia como unidade administrativa (criada em 1621), sendo o Pará e o Maranhão capitanias separadas.

No século XVIII, três governadores quase se sucederam nos governos da Paraíba e do Estado do Maranhão. O primeiro foi João da Maia da Gama, que administrou a Paraíba de 1708 a 1717, voltou a Portugal e retornou em 1722 para assumir o Estado, à frente do qual permaneceu por seis anos. A comissão

\footnotetext{
${ }^{48}$ PITA, Sebastião da Rocha, op. cit., 1976, p. 57. Grifo nosso.

${ }^{49}$ Biblioteca da Ajuda. 54-XI-27, n. ${ }^{\circ}$ 17. Memória das pessoas que desde o princípio da conquista governaram as duas capitanias, do Maranhão e Grão-Pará. 1783, fl. 2.
} 
representou o ápice de sua trajetória, a recompensa de todos os seus préstimos, e o último posto que ocupou no real serviço.

Entre 1722 e 1729, a Paraíba foi governada por João de Abreu Castelo Branco. Nascido por volta de 1675, chegou a estudar na Universidade de Coimbra, mas abandonou-a para servir na Guerra da Liga, durante a qual foi promovido a capitão de Cavalaria. Foi do Conselho Real, cavaleiro professo e comendador das Ordens de Cristo e de Santiago da Espada, distinções que permitem inferir que se tratava de um indivíduo de boa extração social. ${ }^{50}$ Passou pela Ilha da Madeira (1733-1734) e em 1737 tomou posse em São Luís como governador e capitão-general do Estado do Maranhão. ${ }^{51}$ Enquanto governava a Madeira, o capitão-mor da Paraíba era Francisco Pedro de Mendonça Gurjão (1729-1734) que veio a ser o sucessor de João de Abreu Castelo Branco na Madeira (17371747) e no Estado do Maranhão (1747-1751). ${ }^{52}$

Como se vê, na primeira metade do século XVIII, a Paraíba, a Ilha da Madeira e o Estado do Maranhão constituíram um circuito governativo. Castelo Branco e Mendonça Gurjão não provinham de casas titulares. Eram, ao que parece, representantes de uma fração da nobreza lusa detentora de bens de raiz, quiçá usufrutuária de direitos senhoriais. É certo, porém, que possuíam reconhecida folha de serviços. Além disso, tiveram acesso a um governo, o da Madeira, reservado a elementos da aristocracia. ${ }^{53}$

\footnotetext{
${ }^{50} \mathrm{O}$ funeral de João de Abreu Castelo Branco também reforça essa possibilidade. Falecido em $1^{\circ}$ de março de 1748, foi sepultado na Igreja de Santo Estevão de Alfama, "metido em um rico caixão dentro do carneiro sotoposto ao altar da capela-mor". Cf. BARATA, Manoel. Formação histórica do Pará. Belém: Universidade do Pará, 1973, p. 46-47.

${ }^{51}$ Cf. SILVA, Fernando Augusto da; MENESES, Carlos Azevedo de. Elucidário madeirense, vol. 1. $2^{\text {a }}$ ed. Funchal: Tipografia Esperança, 1940-1946, p. 261.

${ }^{52}$ Cf. BARATA, Manoel, op. cit., 1973, p. 47. Ver também SILVA, Fernando Augusto da; MENESES, Carlos Azevedo de, op. cit., 1940-1946, vol. 2, p. 97. O Elucidário não fornece muitos dados sobre Francisco Pedro de Mendonça Gurjão. Apenas diz que os muitos serviços prestados à monarquia foram registrados em sua lápide, na Capela da Quinta de São Lourenço, de sua propriedade, e que o mesmo faleceu aos 83 anos. Ver também Catálogo dos governadores e presidentes da província da Paraíba do Norte. Revista do Instituto Histórico e Geográfico Brasileiro, t. 1, vol. 8. Rio de Janeiro, 1846, p. 81. Um sumário das gestões de João da Maia da Gama, de João de Abreu Castelo Branco e de Francisco Pedro de Mendonça Gurjão pode ser encontrado em BAENA, Antônio Ladislau Monteiro. Compêndio das eras da província do Pará. Belém: Universidade Federal do Pará, 1969, p. 144-148 e p. 151-158.

${ }^{53}$ Cf. MONTEIRO, Nuno Gonçalo. Governadores e capitães-mores do Império atlântico português no século XVIII. In: BICALHO, Maria Fernanda; FERLINI, Vera Lúcia Amaral (orgs.), op. cit., 2005, p. 104.
} 
Diante do exposto, não é difícil mostrar a fragilidade das anotações de Rocha Pita. A começar pelas datas. Se a História da América portuguesa veio a público em 1730 e abrangia fatos ocorridos até 1724, jamais poderia abarcar os deslocamentos de João de Abreu Castelo Branco, Francisco Pedro de Mendonça Gurjão e João da Maia da Gama. Resta investigar se a conexão Paraíba - Estado do Maranhão se fez presente na trajetória administrativa de outros indivíduos, recuando ao século XVII.

Uma Relação dos governadores do Pará e do Maranhão desde a sua fundação até 1783 , contendo um campo denominado "apêndices em serviços e ações", traz o registro dos feitos dos servidores régios nomeados para o Estado do Maranhão. ${ }^{54}$ Considerando-se apenas os indivíduos que governaram no século XVII e poderiam ter servido de referência a Rocha Pita, apurou-se que apenas um esteve na Paraíba antes do Maranhão: Inácio Coelho da Silva, capitão-mor de 1670 a $1673 .{ }^{55}$

A administração do Estado significou a remuneração de serviços prestados durante as guerras e negociações diplomáticas que marcaram o processo de consolidação da independência de Portugal após o fim da União Ibérica. Na mencionada Relação, os governadores do Estado na segunda metade do século XVII foram apresentados com suas respectivas credenciais de serviços. Assim, André Vidal de Negreiros, exceção entre os demais (reinóis) por ter nascido na Paraíba, aparece como aquele que "socorreu Pernambuco na guerra contra os holandeses". O feito - de grande valor para sua folha de serviços - valeu-lhe o governo do Estado do Maranhão entre 1655 e 1656, de Angola e de Pernambuco, este último em duas ocasiões. ${ }^{56}$

Sobre d. Pedro de Melo (1658-1662), diz-se apenas que "serviu no Alentejo na Guerra da Aclamação". Por outro lado, a atuação de outros governadores foi esmiuçada: Rui Vaz de Sequeira (1662-1667) “serviu na praça d'Elvas sitiada pelo marquês de Torreaza"; Antônio de Albuquerque Coelho de Carvalho, o velho (1667-1671), "serviu na Beira na Guerra da Aclamação"; Pedro César de

\footnotetext{
${ }^{54}$ Biblioteca da Ajuda. 54-XI-27, no 17. Relação por mapa dos governadores capitães-generais e dos capitães-mores que governaram o Maranhão e o Pará; e depois esta última distinta e separadamente até 1783 , fl. 25.

${ }^{55}$ LINS, Guilherme Gomes da Silveira d'Ávila. Governantes da Paraíba no Brasil colonial: uma revisão crítica da relação nominal e cronológica (1585-1808). $2^{\mathrm{a}}$ ed. João Pessoa: Edições Fotograf, 2007, p. 84-85.

${ }^{56}$ Biblioteca da Ajuda. 54-XI-27, n. ${ }^{\circ}$ 17. Memória das pessoas que desde o princípio da conquista governaram as duas capitanias, do Maranhão e Grão-Pará. 1783, fl. 9. Ver CORRÊA, Elias Alexandre da Silva. História de Angola, vol. 1. Lisboa: Editorial Ática, 1937, p. 279-274. Ver também MELLO, Evaldo Cabral de, op. cit., 2003, p. 473.
} 
Meneses (1671-1678) "serviu 14 anos em Alentejo na Guerra da Aclamação"; o citado Inácio Coelho da Silva (1678-1682) "na batalha de Montes Claros fez presa nos timbales do príncipe de Parma", enquanto seu sucessor, Francisco de Sá e Meneses (1682-1685), "serviu na Guerra da Aclamação e foi secretário da embaixada à Inglaterra"; Gomes Freire de Andrade, por sua vez, "achou-se na batalha do Ameixial". ${ }^{57}$

Os serviços desempenhados contribuem para demonstrar que a maioria dos agentes mencionados não passou pela Paraíba antes de alcançar o Maranhão. Tais préstimos mostram também que não se tratava de gente de qualidade inferior, como afirmou Pedro Octávio Carneiro da Cunha, ao associar, de maneira superficial, os titulares à qualidade do cargo: "território imenso, população escassa, riqueza quase que apenas potencial, os postos não despertavam o interesse de gente melhor". O historiador elegeu Gomes Freire de Andrade (1685-1687) e Antônio de Albuquerque Coelho de Carvalho, o moço (1690-1701), como figuras de destaque; o primeiro por ter debelado a Revolta de Beckman e o segundo pela abertura do caminho terrestre ligando São Luís a Salvador. E considerava os antecessores de ambos "figuras secundárias". 58

Diferentemente da caracterização de Carneiro da Cunha, os governadores considerados eram militares experientes, requisito fundamental para atuar na região amazônica, e sua escolha consistiu na remuneração da Coroa pelos serviços prestados nas guerras da Restauração, episódio fundador na história lusa, cujo desfecho ratificou a independência de Portugal em relação à Espanha. Não eram representantes da fidalguia titulada, mas suas folhas de serviços traziam a marca indelével da participação na elevação e na defesa da dinastia que então reinava. Partilhavam, portanto, da mesma experiência no real serviço.

Rui Vaz de Sequeira provou seu valor em momento dramático do processo de Restauração, quando a praça de Elvas esteve sob ameaça dos espanhóis que durante dois anos cercaram as fortalezas do Alentejo e do Minho. Em 1659, dezenove anos depois da aclamação de d. João IV, a vitória portuguesa na Batalha das Linhas de Elvas - "um dom da providência" nas palavras de Joaquim Veríssimo Serrão - afastou temporariamente as pretensões de Filipe IV sobre o

\footnotetext{
${ }^{57}$ Biblioteca da Ajuda. 54-XI-27, no 17. Relação por mapa..., fl. 25.

${ }^{58}$ CUNHA, Pedro Octávio Carneiro da. Política e administração de 1640 a 1763. In. HOLANDA, Sérgio Buarque de (dir.). História geral da civilização brasileira, t. 1, vol. 2. $10^{\mathrm{a}}$ ed. Rio de Janeiro: Bertrand Brasil, 2003, p. 29 e p. 31.
} 
território luso. ${ }^{59}$ A vitória das tropas fiéis a d. João IV tornou-se digna de nota justamente pela dificuldade de recrutar soldados e pela duração do cerco, ${ }^{60}$ cumulando os participantes do feito de uma glória singular.

Francisco de Sá e Meneses assistiu de perto a um episódio crucial para o sucesso da Restauração. Em troca do apoio militar inglês - essencial para conter os espanhóis - a infanta d. Catarina, filha de d. João IV, já falecido, foi dada em casamento ao rei Carlos II. A embaixada encarregada de negociar a aliança ratificou, em 1661, o compromisso português de conceder uma vultosa soma em dinheiro e as valiosas praças de Tânger (África) e de Bombaim (Índia) como dote de d. Catarina, além de privilégios aos negociantes ingleses em algumas partes da América. ${ }^{61}$

O acontecimento no qual Francisco de Sá e Meneses tomou parte antecedeu a famosa Batalha do Ameixial. Neste evento, o exército comandado por d. Sancho Manuel de Vilhena, $1^{\circ}$ conde de Vila Flor, derrotou as tropas de d. João de Áustria que tinham avançado sobre o Alentejo e colocavam Lisboa sob ameaça. No calor da Batalha de Montes Claros, que encerrou as guerras da Restauração, em julho de 1665, Inácio Coelho da Silva realizou a proeza de capturar inimigos que deviam estar próximos dos timbales, instrumentos de percussão defendidos com o mesmo vigor que os estandartes no campo de batalha. $\mathrm{O}$ registro amiúde do feito conferiu realce à ação do militar.

A análise das trajetórias de outros homens que também exerceram a função governativa nas conquistas do Norte contribui para a discussão da afirmativa de Rocha Pita de que "muitos" foram promovidos da Paraíba ao Estado do Maranhão. Fernão Carrilho (1701-1702), Manuel Rolim de Moura (1702-1705), Bernardo Pereira de Berredo (1718-1722) e Alexandre de Sousa Freire (1728-1732) governaram o Estado na primeira metade do século XVIII, mas os dois últimos, obviamente, não poderiam ter sido contemplados por Rocha Pita em sua narrativa histórica.

Experiente no embate com índios hostis e na destruição de mocambos de negros fugidos nos sertões de Sergipe, da Bahia, de Pernambuco (comandou três incursões ao Quilombo de Palmares) e Ceará, Fernão Carrilho acumulou serviços que, a despeito da ausência de qualquer preparo militar formal, não

\footnotetext{
${ }^{59}$ SERRÃO, Joaquim Veríssimo. O tempo dos Filipes em Portugal e no Brasil (1580-1668). $2^{\mathrm{a}}$ ed. Lisboa: Edições Colibri, 2004, p. 43.

${ }^{60}$ Cf. COSTA, Fernando Dores. A nobreza é uma elite militar? O caso Cantanhede-Marialva em 1658-1665. In: MONTEIRO, Nuno Gonçalo; CARDIM, Pedro; CUNHA, Mafalda Soares da (orgs.). Optima pars: elites ibero-americanas do Antigo Regime. Lisboa: ICS, 2005, p. 185-187.

${ }^{61}$ Cf. SERRÃO, Joaquim Veríssimo, op. cit., 2004, p. 43-44.
} 
o tornaram menos útil aos interesses metropolitanos no Maranhão. Era um "soldado da fortuna" (dotado de experiência militar, mas sem distinção de nascimento) ${ }^{62}$ que antes de chegar a São Luís concorreu três vezes ao cargo de capitão-mor do Ceará, sendo finalmente escolhido pelo Conselho Ultramarino em 1699. Declinou do posto para servir de lugar-tenente a Antônio de Albuquerque Coelho de Carvalho, o moço, então governador e capitão-general do Estado. E, no impedimento deste, Carrilho assumiu interinamente. ${ }^{63}$

Um dos feitos mais notáveis da carreira de Manuel Rolim de Moura, que "serviu nas Armadas", foi o de ir em "socorro a Ceuta". ${ }^{64}$ Como capitão de Infantaria, participou, em 1694, ao lado de d. Pedro de Mascarenhas, $1^{\circ}$ conde de Sandomil, dos esforços empreendidos pelos portugueses para auxiliar a Espanha no cerco àquela praça, assolada por piratas. ${ }^{65}$ É bastante aceitável que a façanha tenha permitido a Rolim de Moura, formado em Cânones antes de se engajar na tropa ${ }^{66}$ o desempenho da função governativa.

O capitão de cavalos Bernardo Pereira de Berredo e Castro "achou-se na batalha d'Almenara", durante a Guerra da Sucessão Espanhola. O Estado do Maranhão foi seu primeiro destino na administração ultramarina. Depois de quatro anos no governo em São Luís e de mais algum tempo necessário à conclusão dos Anais históricos do Estado do Maranhão, retornou a Portugal. Encerrou a carreira na praça africana de Mazagão. ${ }^{67}$

Alexandre de Sousa Freire foi colegial de S. Paulo, porém, desistiu da vida religiosa para se engajar no Exército. Acompanhou o pai, Bernardino de Távora de Sousa Tavares, quando este foi governador de Mazagão e de Angola. Como mestre-de-campo, Sousa Freire combateu os mouros que ameaçavam a praça

\footnotetext{
${ }^{62}$ MONTEIRO, Nuno Gonçalo. Trajetórias sociais e governo das conquistas... In: FRAGOSO, João; BICALHO, Maria Fernanda; GOUVÊA, Maria de Fátima (orgs.), op. cit., 2001, p. 257.

${ }^{63}$ Cf. BAENA, Antônio Ladislau Monteiro, op. cit., 1969, p. 131-133. Ver também SANTOS, Fabiano Vilaça dos. Feitos de armas e efeitos de recompensa: perfil do sertanista Fernão Carrilho. Anais da XXIII Reunião Anual da SBPH. Curitiba: SBPH, 2004, p. 209-215.

${ }^{64}$ Biblioteca da Ajuda. 54-XI-27, $\mathrm{n}^{\circ}$ 17. Relação por mapa..., fl. 25.

${ }^{65} \mathrm{Cf}$. BERREDO, Bernardo Pereira de. Anais históricos do Estado do Maranhão. $3^{\mathrm{a}}$ ed. Florença: Tipografia Barbera, 1905, vol. 2, p. 301-302.

${ }^{66}$ Cf. BARATA, Manoel, op. cit., 1973, p. 106.

${ }^{67}$ Biblioteca da Ajuda. 54-XI-27, no 17. Relação por mapa..., fl. 25. Ver RAMINELLI, Ronald. Bernardo Pereira de Berredo. In: VAINFAS, Ronaldo (dir.). Dicionário do Brasil colonial (15001808). Rio de Janeiro: Objetiva, 2000. Ver também SANTOS, Fabiano Vilaça dos. A reação dos "cidadãos" do Estado do Maranhão aos "maus procedimentos" do governador João da Maia da Gama (1722-1728). Anais da XXIV Reunião Anual da SBPH. Curitiba: SBPH, 2005, p. 149-155.
} 
marroquina. Mais tarde circulou pela Bahia, aonde continuou servindo como militar, adquiriu terras e veio a falecer. Em suma, seus contatos com a realidade da administração colonial, somados à formação militar, constituíram a experiência que respaldou a sua indicação para o Estado do Maranhão. ${ }^{68}$

Com base nas trajetórias dos personagens que atuaram nas conquistas do Norte na segunda metade do século XVII e na primeira metade do XVIII, é possível afirmar que houve certo exagero de Rocha Pita ao enunciar a articulação entre os governos da Paraíba e do Maranhão. A maioria dos agentes designados para o Estado assumia pela primeira vez a função governativa, em decorrência de seus méritos no campo de batalha durante as guerras de Restauração ou na Guerra da Sucessão Espanhola. Enquadravam-se no perfil delineado no século XIX por João Francisco Lisboa, para quem os governadores do Estado do Maranhão eram "escolhidos ordinariamente na classe dos militares". ${ }^{69}$

A conexão Paraíba - Estado do Maranhão encerrou-se quando Francisco Pedro de Mendonça Gurjão entregou o cargo a Francisco Xavier de Mendonça Furtado, em 1751. Porém, não ficou totalmente fora de cogitação. Anos depois, o circuito foi lembrado no requerimento de José Bernardo Galvão, um militar de Santa Catarina promovido a capitão de dragões para servir no Rio Grande de São Pedro. Em carta a Diogo de Mendonça Corte Real, agradeceu a mercê e pediu a intercessão do secretário de Estado para que obtivesse a "patente para governador ou do Maranhão ou da Paraíba do Norte", onde sua experiência militar poderia ser útil. ${ }^{70}$

\section{Considerações finais}

Os percursos de administradores coloniais no circuito Paraíba - Estado do Maranhão foram menos frequentes do que indicou Sebastião da Rocha Pita. Todavia, o cronista estava certo em um aspecto crucial: o primeiro posto (o governo da Paraíba) representou um "degrau", uma via de ascensão ou promoção na administração colonial. Com isso, Rocha Pita contribuiu para a percepção da existên-

\footnotetext{
${ }^{68}$ Sobre o governo de Bernardino de Távora de Sousa Tavares em Angola, ver GONZAGA, Norberto. História de Angola (1482-1963). [Luanda]: Centro de Informação e Turismo de Angola, [s. d.], p. 247. Ver também MARQUES, César Augusto. Dicionário histórico-geográfico da província do Maranhão. Rio de Janeiro: Editora Fon-Fon \& Seleta, 1970, p. 335-336. SANTOS, Fabiano Vilaça dos. Pedras do ofício: Alexandre de Sousa Freire e os jesuítas no Estado do Maranhão (1728-1732). Anais da XXV Reunião Anual da SBPH. Rio de Janeiro: SBPH, 2006, p. 275-282. ${ }^{69}$ LISBOA, João Francisco. Crônica do Brasil colonial: apontamentos para a história do Maranhão. Petrópolis: Vozes; Brasília: INL, 1976, p. 377.

${ }^{70}$ AHU - Projeto Resgate. Santa Catarina (avulsos), cd 1, cx. 2, doc. 103. Carta de 6 de novembro de 1754.
} 
cia, em particular na América portuguesa, de conexões que articulavam governos de maior prestígio (como Bahia, Pernambuco, Rio de Janeiro, Minas Gerais), e outras que associavam capitanias de menor expressão, a exemplo da Paraíba e do Maranhão, sede de uma unidade administrativa independente do Estado do Brasil.

É importante sublinhar que o circuito aqui privilegiado, presente em poucas trajetórias no real serviço, ficou quase restrito à primeira metade do século XVIII. E desapareceu a partir de 1751, quando uma nova configuração administrativa foi imposta às conquistas do Norte. O surgimento do Estado do Grão-Pará e Maranhão, com sede em Belém do Pará, em função das demandas da colonização amazônica - a redefinição do lugar do índio na sociedade, a revitalização da agricultura e do comércio (mediante a criação de uma companhia monopolista) ou a delimitação das fronteiras entre domínios portugueses e espanhóis - foi acompanhado de mudanças no perfil dos governantes e trouxe novas possibilidades de deslocamentos na administração colonial.

\section{Referências bibliográficas}

ABREU, João Capistrano de. Capítulos de história colonial: 1500-1800. $6^{\text {a }}$ ed. Rio de Janeiro: Civilização Brasileira; Brasília: INL, 1976.

ALMEIDA, Horácio de. História da Paraíba, t. 1. João Pessoa: Imprensa Universitária, 1966.

ANDRADE, Delmiro Pereira de. Evolução histórica da Paraíba do Norte. Rio de Janeiro: Ed. Minerva, 1946.

BAENA, Antônio Ladislau Monteiro. Compêndio das eras da Província do Pará. Belém: Universidade Federal do Pará, 1969.

BARATA, Manoel. Formação histórica do Pará. Belém: Universidade Federal do Pará, 1973.

BERREDO, Bernardo Pereira de. Anais históricos do Estado do Maranhão, vols. 1 e 2. $3^{\text {a }}$ ed. Florença: Tipografia Barbera, 1905.

CANEDO, Francisco de Castro da Silva. A descendência portuguesa de el rei d. João II, vol. 1. 2ª ed. Braga: Edições Carvalhos de Basto, 1993.

CORRÊA, Elias Alexandre da Silva. História de Angola, vol. 1. Lisboa: Editorial Ática, 1937.

CORTESÃO, Jaime. História da expansão portuguesa. Lisboa: Imprensa Nacional; Casa da Moeda, 1993.

COSTA, Fernando Dores. A nobreza é uma elite militar? O caso CantanhedeMarialva em 1658-1665. In: MONTEIRO, Nuno Gonçalo; CARDIM, Pedro; CUNHA, Mafalda Soares da (orgs.). Optima pars: elites ibero-americanas do 
Antigo Regime. Lisboa: ICS, 2005, p. 47-63.

CUNHA, Mafalda Soares da. Governo e governantes do Império português do Atlântico (século XVII). In: BICALHO, Maria Fernanda; FERLINI, Vera Lúcia Amaral (orgs.). Modos de governar: ideias e práticas políticas no Império português (séculos XVI a XIX). São Paulo: Alameda, 2005, p. 69-92.

CUNHA, Mafalda Soares da; MONTEIRO, Nuno Gonçalo. Vice-reis, governadores e conselheiros de governo do Estado da Índia (1505-1834). Recrutamento e caracterização social. Penélope n. ${ }^{\circ}$ 15. Lisboa, 1995, p. 91-120.

CUNHA, Pedro Octávio Carneiro da. Política e administração de 1640 a 1763. In: HOLANDA, Sérgio Buarque de (dir.). História geral da civilização brasileira, t. 1, vol. 2. $10^{\mathrm{a}}$ ed. Rio de Janeiro: Bertrand Brasil, 2003, p. 15-54.

FLORES, Maria Bernadete Ramos; SERPA, Élio (orgs.). Catálogo de documentos avulsos manuscritos referentes à capitania de Santa Catarina - 1717-1827. Florianópolis: UFSC, 2000.

FRAGOSO, João Luís Ribeiro; GOUVÊA, Maria de Fátima Silva; BICALHO, Maria Fernanda Baptista. Uma leitura do Brasil colonial: bases da materialidade e da governabilidade no Império. Penélope, n. ${ }^{\circ} 23$. Oeiras, 2000, p. 67-88.

GAYO, Felgueiras. Nobiliário das famílias de Portugal. $2^{\mathrm{a}}$ ed. Braga: Edições Carvalhos de Basto, 1989.

GONZAGA, Norberto. História de Angola (1482-1963). [Luanda]: Centro de Informação e Turismo de Angola, s/d.

LINS, Guilherme Gomes da Silveira d'Ávila. Governantes da Paraíba no Brasil colonial: uma revisão crítica da relação nominal e cronológica (1585-1808). $2^{\mathrm{a}}$ ed. João Pessoa: Edições Fotograf, 2007.

LISBOA, João Francisco. Crônica do Brasil colonial: apontamentos para a história do Maranhão. Petrópolis: Vozes; Brasília: INL, 1976.

MARQUES, César Augusto. Dicionário histórico-geográfico da Província do Maranhão. Rio de Janeiro: Editora Fon-Fon \& Seleta, 1970.

MARTINS, F. A. Oliveira. Um herói esquecido (João da Maia da Gama), vol. 1. Lisboa: Agência Geral das Colônias, 1944.

MELLO, Evaldo Cabral de. A fronda dos mazombos: nobres contra mascates, Pernambuco, 1666-1715. $2^{\mathrm{a}}$ ed. São Paulo: Editora 34, 2003.

MELLO, Evaldo Cabral de. Rubro veio: o imaginário da restauração pernambucana. $2^{\mathrm{a}}$ ed. Rio de Janeiro: Topbooks, 1997.

MENDONÇA, Marcos Carneiro de (coord). A Amazônia na era pombalina. Correspondência inédita do governador e capitão-general do Estado do Grão-Pará e Maranhão Francisco Xavier de Mendonça Furtado (1751-1759), t. 1. São Paulo: Instituto Histórico e Geográfico Brasileiro, 1963.

MENEZES, Mozart Vergetti de. Sonhar com o céu, padecer no inferno: governo e 
sociedade na Paraíba do século XVIII. In: BICALHO, Maria Fernanda; FERLINI, Vera Lúcia Amaral (orgs.). Modos de governar: ideias e práticas políticas no Império português (séculos XVI a XIX). São Paulo: Alameda, 2005, p. 327-340.

MONTEIRO, Nuno Gonçalo. O crepúsculo dos grandes. A Casa e o patrimônio da aristocracia em Portugal (1750-1832). $2^{\mathrm{a}}$ ed. Lisboa: Imprensa Nacional; Casa da Moeda, 2003.

MONTEIRO, Nuno Gonçalo. Elites e poder: entre o Antigo Regime e o liberalismo. Lisboa: Imprensa de Ciências Sociais; Instituto de Ciências Sociais da Universidade de Lisboa, 2003.

MONTEIRO, Nuno Gonçalo. Governadores e capitães-mores do Império atlântico português no século XVIII. In: BICALHO, Maria Fernanda; FERLINI, Vera Lúcia Amaral (orgs.). Modos de governar: ideias e práticas políticas no Império português (séculos XVI a XIX). São Paulo: Alameda, 2005, p. 93-115.

MONTEIRO, Nuno Gonçalo. Poder senhorial, estatuto nobiliárquico e aristocracia. In: HESPANHA, Antônio Manuel (coord.). História de Portugal - vol. 4: O Antigo Regime. Lisboa: Editorial Estampa, 1998, p. 297-338.

MONTEIRO, Nuno Gonçalo. Trajetórias sociais e governo das conquistas: notas preliminares sobre os vice-reis e governadores-gerais do Brasil e da Índia nos séculos XVII e XVIII. In: FRAGOSO, João; BICALHO, Maria Fernanda; GOUVÊA, Maria de Fátima (orgs.). O Antigo Regime nos trópicos: a dinâmica imperial portuguesa (séculos XVI-XVIII). Rio de Janeiro: Civilização Brasileira, 2001, p. 249-283.

OLIVEIRA, Elza Régis de; MENEZES, Mozart Vergetti de; LIMA, Maria da Vitória Barbosa (orgs.). Catálogo de documentos manuscritos avulsos referentes à Capitania da Paraíba, existentes no Arquivo Histórico Ultramarino de Lisboa. João Pessoa: Editora Universitária/UFPB, 2001.

OLIVEIRA, Elza Régis de. Paraíba, capitania da. In: SILVA, Maria Beatriz Nizza da (coord.). Dicionário da história da colonização portuguesa no Brasil. Lisboa: Editorial Verbo, 1994.

PAIVA, José Pedro. Os bispos de Portugal e do Império, 1495-1777. Coimbra: Imprensa da Universidade, 2006.

PITA, Sebastião da Rocha. História da América portuguesa, desde o ano de 1500 do seu descobrimento atéo de 1724. Belo Horizonte: Ed. Itatiaia; São Paulo: Edusp, 1976.

RAMINELLI, Ronald. Bernardo Pereira de Berredo. In: VAINFAS, Ronaldo (dir.). Dicionário do Brasil colonial (1500-1808). Rio de Janeiro: Objetiva, 2000.

RUSSELL-WOOD, A. J. R. Governantes e agentes. In: BETHENCOURT, Francisco; CHAUDHURI, Kirti (orgs.). História da expansão portuguesa, vol. 3. Lisboa: Círculo dos Leitores, 1998, p. 169-192.

RUSSELL-WOOD, A. J. R. Um mundo em movimento: os portugueses na África, Ásia e América (1415-1808). Tradução de Vanda Anastácio. Lisboa: Difel, 1998. 
SANTOS, Fabiano Vilaça dos. Feitos de armas e efeitos de recompensa: perfil do sertanista Fernão Carrilho. Anais da XXIII Reunião Anual da SBPH. Curitiba: SBPH, 2004, p. 209-215.

SANTOS, Fabiano Vilaça dos. O governo das conquistas do norte: trajetórias administrativas no Estado do Grão-Pará e Maranhão (1751-1780). Tese de doutorado, FFLCH, Universidade de São Paulo, 2008.

SANTOS, Fabiano Vilaça dos. Mediações entre a fidalguia portuguesa e o marquês de Pombal: o exemplo da Casa de Lavradio. Revista Brasileira de História, vol. 24, n. ${ }^{\circ}$ 48. São Paulo, 2004, p. 321-329.

SANTOS, Fabiano Vilaça dos. Pedras do ofício: Alexandre de Sousa Freire e os jesuítas no Estado do Maranhão (1728-1732). Anais da XXV Reunião Anual da SBPH. Rio de Janeiro: SBPH, 2006, p. 275-282.

SANTOS, Fabiano Vilaça dos. A reação dos "cidadãos" do Estado do Maranhão aos "maus procedimentos" do governador João da Maia da Gama (1722-1728). Anais da XXIV Reunião Anual da SBPH. Curitiba: SBPH, 2005, p. 149-155.

SERRÃO, Joaquim Veríssimo. O tempo dos Filipes em Portugal e no Brasil (15801668). $2^{\mathrm{a}}$ ed. Lisboa: Edições Colibri, 2004.

SILVA, Fernando Augusto da; MENESES, Carlos Azevedo de. Elucidário madeirense, vols. 1 e 2. $2^{\mathrm{a}}$ ed. Funchal: Tipografia Esperança, 1940-1946.

SOUSA, D. Antônio Caetano de. História genealógica da Casa Real portuguesa. $2^{\mathrm{a}}$ ed. Coimbra: Atlântida, 1946.

SOUTHEY, Robert. História do Brasil, vol. 1. Tradução de Luís Joaquim de Oliveira e Castro. Belo Horizonte: Ed. Itatiaia; São Paulo: Edusp, 1981.

SOUZA, Laura de Mello e. O sol e a sombra: política e administração na América portuguesa do século XVIII. São Paulo: Companhia das Letras, 2006.

WEHLING, Maria José Mesquita Cavaleiro de Macedo. O Estado do Maranhão na União Ibérica. Revista do Instituto Histórico e Geográfico Brasileiro, 166 (426), jan./mar. Rio de Janeiro, 2005, p. 57-86.

ZÜQUETE, Afonso Eduardo Martins. Nobreza de Portugal e do Brasil. $3^{\mathrm{a}}$ ed. Lisboa: Edições Zairol, 2000.

ZÜQUETE, Afonso Eduardo Martins. Tratado de todos os vice-reis e governadores da Índia. Lisboa: Editorial Enciclopédia, 1962.

Recebido: julho/2008 - Aprovado: junho/2009. 